Article

\title{
Products and Mechanistic Investigations on the Reactions of Hydrazines with Ozone in Gas-Phase
}

\author{
Dan Huang ${ }^{1}$, Xiangxuan Liu ${ }^{1}$, Zheng Xie ${ }^{1, *(\mathbb{D}}$, Xuanjun Wang ${ }^{1}$, Xin Gao ${ }^{2}$ and Yuxue Yang ${ }^{1}$ \\ 1 High-Tech Institute of Xi'an, Xi'an 710025, China; huangdanyyn08@sina.com (D.H.); \\ liuxx1964@sina.com (X.L.); wangxj503@sina.com (X.W.); 18782091393@163.com (Y.Y.) \\ 2 High-Tech Institute of Beijing, Beijing 10085, China; gaoxx06@sina.com \\ * Correspondence: xiezheng10@tsinghua.org.cn
}

Received: 30 July 2018; Accepted: 6 September 2018; Published: 11 September 2018

\begin{abstract}
The toxic transformation products of hydrazines are of great concern. These products' properties combined with their formation mechanisms are needed to assess their potential environmental and human impacts. In this study, the gas-phase reaction of hydrazine $\left(\mathrm{N}_{2} \mathrm{H}_{4}\right)$, monomethyldrazine $(\mathrm{MMH})$ and unsymmetrical dimethyhydrazine (UDMH) with $\mathrm{O}_{3}$ have been studied at varying reactant ratios, both in the presence and absence of a radical trap. Gas chromatography-mass spectroscopy (GC-MS) has been implied to follow reactant consumption and product formation. Apart from the reported products detected by Fourier transform infrared spectroscopy (FT-IR), the newly found compounds (hydrazones, formamides, dimethylamine, 1,1,4,4-tetramethyl-1,2-tetrazene,dimethylamino-acetonitrile, $\mathrm{N}_{2}, \mathrm{H}_{2} \mathrm{O}$, et al.) are identified by GC-MS . The relative yields of the organic products vary considerably at different $\mathrm{O}_{3} / \mathrm{MMH}$ or UDMH ratios. UDMH and $\mathrm{MMH}$ are confirmed as high potential precursors of N-nitrosodimethylamine (NDMA). The presence of hydroxyl radicals (HO-) hinders NDMA formation in $\mathrm{MMH}-\mathrm{O}_{3}$ system. Meanwhile, it increases NDMA formation in $\mathrm{UDMH}-\mathrm{O}_{3}$ system. The suggested reaction mechanisms which account for the observed products are discussed.
\end{abstract}

Keywords: hydrazines; ozone; products; mechanism

\section{Introduction}

Hydrazine $\left(\mathrm{N}_{2} \mathrm{H}_{4}\right)$ and its alkyl derivatives, monomethyldrazine (MMH) and unsymmetrical dimethylhydrazine (UDMH) have been the main high-energy fuels for rocket launching for decades. Considering these compounds are used in large quantity every year, the releases to the atmosphere stemming from storage, transportation and filling cannot be ignored [1]. The hydrazines themselves are hazards to humans. The American Conference of Governmental Industrial Hygienist (ACGIH) has recommended that the threshold limit values (TLVs) for $\mathrm{N}_{2} \mathrm{H}_{4}, \mathrm{MMH}$, and UDMH be lowered from 100, 200 and $500 \mathrm{ppb}$, respectively, to $10 \mathrm{ppb}$ in air [2,3]. A major concern is that the toxicity of considerable amounts of the huge list of transformation products are equal to or greater than that of the hydrazines themselves [4,5]. N-nitrosodimethylamine (NDMA) can be taken as an example, whose theoretical cancer risk level is $0.7 \mathrm{ng} / \mathrm{m}^{3}$ in air [6].

In order to explore the atmospheric fate of these chemicals, lots of studies have been done to obtain chemical properties and formation mechanism of transformation products. Since the hydrazines cannot be photolyzed in the solar actinic region $(\lambda>290 \mathrm{~nm})$, their likely reaction pathways in the atmosphere are reaction with ozone and hydroxyl radical. In the 1980's, The rate constants for the reactions of hydroxyl radical, ozone with all three of the hydrazines have been measured by the Statewide Air pollution Reasearch Center (SAPRC) of the University of California at Riverside [7]. The results show that all three of the hydrazines could be rapidly consumed by 
reactions with ozone as well as by reactions with hydroxyl radicals [8]. The specific ozonation products observed in this laboratory are $\mathrm{H}_{2} \mathrm{O}_{2}$ and $\mathrm{N}_{2} \mathrm{O}$ from $\mathrm{N}_{2} \mathrm{H}_{4}$; methyl hydroperoxide, methyldiazene, diazomethane, $\mathrm{HCHO}, \mathrm{CH}_{3} \mathrm{OH}$ from $\mathrm{MMH}$; NDMA in large yields from UDMH [9]. The reaction of UDMH with ozone is of great interest because it leads to a high yields of NDMA [10-12]. The NDMA formation mechanism from UDMH ozonation has been investigated by theoretical calculations [13,14]. The NDMA formation pathways include hydrogen atom abstraction and direct oxygen atom addition [15]. The results also indicate that HO. plays a key role in promoting NDMA formation. However, the experiment shows that the radical traps increase the NDMA formation [11]. Furthermore, various analytical techniques such as high performance liquid chromatography-mass spectroscopy (HPLC-MS) [16-18], gas chromatography-mass spectroscopy (GC-MS) [3,19,20], and solid phase micro-extraction (SPME-GC/MS) [21] have been used for the identification and quantitative determination of these transformation products, and more than 30 oxidative products have been identified. However, the information about the products of the hydrazines reaction with ozone is scarce, and the HO. influence on NDMA formation mechanism is still in discussion. In order to find more products and more deeply understand the mechanism of the hydrazines reaction with ozone, GC-MS is utilized to follow reactant consumption and product formation. The reactions of $\mathrm{N}_{2} \mathrm{H}_{4}, \mathrm{MMH}$, and UDMH with $\mathrm{O}_{3}$ are investigated at varying reactant ratios, both in the presence and absence of radical traps. Meanwhile, the information of the highest occupied molecular orbital (HOMO) has been found to account for the possible attack sites of $\mathrm{N}_{2} \mathrm{H}_{4}, \mathrm{MMH}$, UDMH by ozone. Moreover, the formation mechanisms of the major detected products have been discussed.

\section{Experimental Section}

\subsection{Reaction Chamber and GC-MS System}

The experiments were carried out using a chamber (internal volume of $500 \mathrm{~mL}$, cylinder). The detailed schematic diagram of this apparatus is provided in Figure 1.

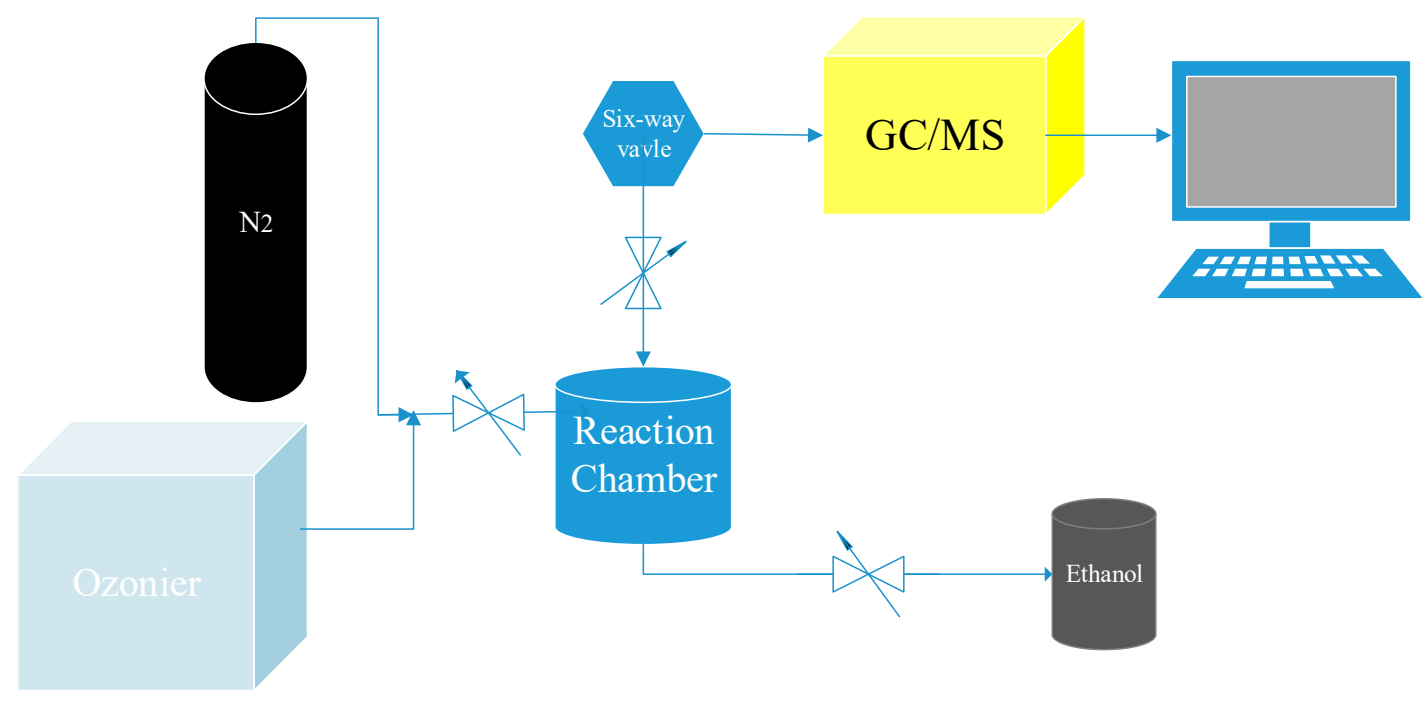

Figure 1. Schematic diagram of the main experimental apparatus.

\subsection{Materials}

Anhydrous hydrazine (stated purity 97+\%, Henan Liming Chemical Reagent Co., Zhengzhou, China), methylhydrazine (98\%, Henan Liming Chemical Reagent Co., China), and unsymmetrical dimethylhydrazine (99+\%, Henan Liming Chemical Reagent Co., China) were commercial available. Ozone was produced in a laboratory ozonizer with oxygen source (Model FL-810ET, Shenzhen Feili Electric Technology Co., Shenzhen, China). 


\subsection{Products Analysis}

Before each runs, the reaction chamber was flushed with the pure $\mathrm{N}_{2}$. The blanked sample was analyzed to make sure that the gas in the reaction chamber was pure. Then the reaction chamber (500 mL, cylinder) was evacuated. The samples $\left(\mathrm{N}_{2} \mathrm{H}_{4} 10 \mu \mathrm{L}\right.$, MMH $10 \mu \mathrm{L}$, UDMH $10 \mu \mathrm{L}$ ) were injected into it. After $5 \mathrm{~min}$, the chamber was flushed with different concentration ozone until the pressure reaches 1.8 bar pressure. Then the reacted samples were detected by the GC-MS through the six-way valve on line. To further investigate the intermediate reaction in the presence of $\mathrm{O}_{3}$, the chamber was flushed with $\mathrm{O}_{3}$ after the experiments of each sample. Each operation was repeated three times. The reaction chamber was thoroughly flushed with the pure $\mathrm{N}_{2}$, and the exhaust gas was washed with ethanol solution to remove the toxic gas (NDMA, etc.). Each sample was detected through GC-MS (7890A-5795C, Agilent, Santa Clara, CA, USA), based on the calibrated internal standards. Separation was performed on a DB-225S $(30 \mathrm{~m} \times 250 \mu \mathrm{m} \times 0.25 \mu \mathrm{m})$ capillary column. The conditions of the GC-MS were as follows: helium as the carrier gas at a rate of $1.5 \mathrm{~mL} / \mathrm{min}$, the temperature of the injector $35^{\circ} \mathrm{C}$, column from $35^{\circ} \mathrm{C}$ to $150{ }^{\circ} \mathrm{C}$ with a rate of $10^{\circ} \mathrm{C} / \mathrm{min}$; the split ratio 1:1.

\section{Results and Discussion}

\subsection{The Reactions between HH with Ozone}

Figure 2 shows the final products of $\mathrm{N}_{2} \mathrm{H}_{4}$ during ozonation detected by GC-MS. The major products are listed in Table 1 . The products detected in the reaction of $\mathrm{O}_{3}$ with hydrazine are $\mathrm{H}_{2} \mathrm{O}$, $\mathrm{N}_{2}$ and $\mathrm{N}_{2} \mathrm{O}$. Compared to the product observed by FT-IR, $\mathrm{H}_{2} \mathrm{O}$ and $\mathrm{N}_{2}$ are newly discovered products and the $\mathrm{N}_{2} \mathrm{O}$ is relatively minor too. $\mathrm{NO}_{\mathrm{x}}\left(\mathrm{NO}\right.$ or $\left.\mathrm{NO}_{2}\right)$ is also not detected. Based on the products, we can propose that the oxidation of $\mathrm{NH}_{2}$ group is initiated by hydrogen atom abstraction rather than by direct oxygen atom addition. Therefore, the ultimate fates of $\mathrm{N}_{2} \mathrm{H}_{4}$ reaction with ozone are $\mathrm{N}_{2}$ and $\mathrm{H}_{2} \mathrm{O}$. The release of $\mathrm{N}_{2} \mathrm{H}_{4}$ will probably have little effect on the levels of $\mathrm{NO}_{x}$, nitrates in the atmosphere.

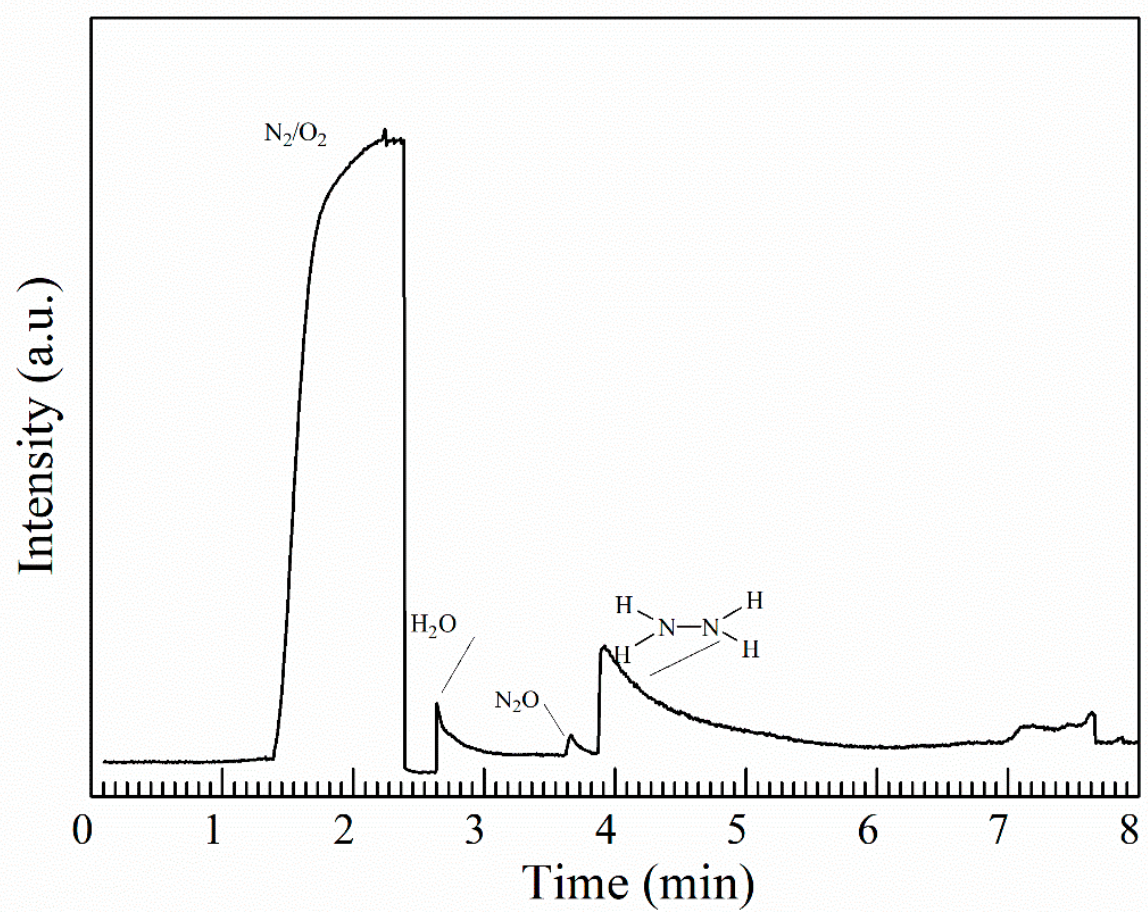

Figure 2. Gas chromatogram of the ozonation products of hydrazine. 
Table 1. Products of the reaction of hydrazine with ozone.

\begin{tabular}{cccc}
\hline Product & Peak/min & CAS & Pro. \\
\hline $\mathrm{N}_{2}$ & 2.236 & $7727-37-9$ & 60.4 \\
$\mathrm{H}_{2} \mathrm{O}$ & 2.571 & $7732-18-5$ & 98.2 \\
$\mathrm{~N}_{2} \mathrm{O}$ & 3.657 & $10024-97-2$ & 30.8 \\
$\mathrm{~N}_{2} \mathrm{H}_{4}$ & 3.983 & $302-01-2$ & 93.2 \\
\hline
\end{tabular}

\subsection{The Reactions between MMH with Ozone}

\subsubsection{Products}

Figure 3 shows that the final products are detected at vary $\mathrm{O}_{3} / \mathrm{MMH}$ ratios. The detailed information of all the products is listed in Table 2. As shown in Table 2, the mixture of products in the $\mathrm{MMH}+\mathrm{O}_{3}$ system detected by GC-MS is more complex than that observed by FT-IR. The number of the various oxidation products reaches 16 .
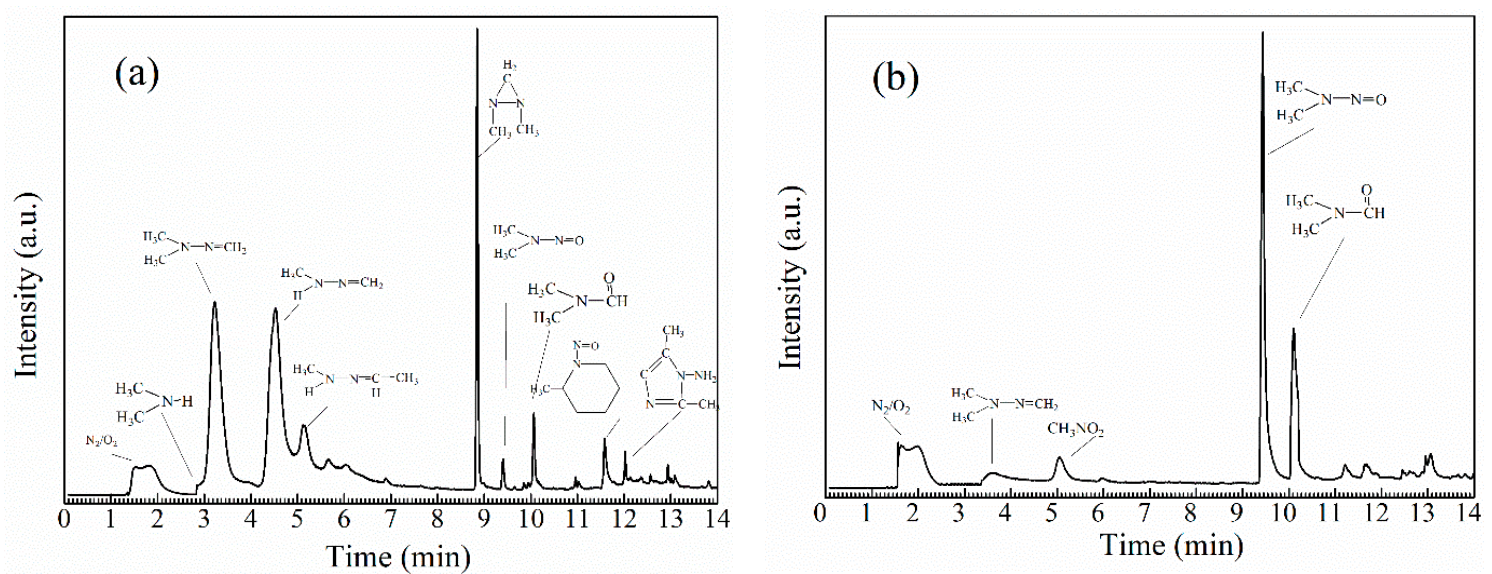

Figure 3. Gas chromatogram of the ozonation products of methylhydrazine: (a) $\mathrm{O}_{3} / \mathrm{MMH} \approx 1: 1$; (b) $\mathrm{O}_{3} / \mathrm{MMH} \approx 10: 1$.

Table 2. Products of the reaction of hydrazine with ozone.

\begin{tabular}{lccc}
\hline Product & Peak/min & CAS No. & Pro. \\
\hline $\mathrm{N}_{2}$ & 2.241 & $7727-37-9$ & 98.0 \\
$\mathrm{H}_{2} \mathrm{O}$ & 2.740 & $7732-18-5$ & 97.2 \\
Dimethylamine (DMA) & 2.438 & $124-40-3$ & 70.5 \\
Formaldehyde dimethylhydrazone (FDMH) & 3.276 & $2035-89-4$ & 91.4 \\
Formaldehyde monomethylhydrazone (FMH) & 4.646 & $36214-48-9$ & 30.5 \\
Acetadehyde methydrazone (AMH) & 5.687 & $17167-73-6$ & 35.5 \\
$N, N$-tetramethyl-Methanediamine & 7.430 & $51-80-9$ & 10.8 \\
1,2-dimethyldiaziridine (DDZ) & 8.859 & $6794-95-2$ & 20.1 \\
$N$-nitrododimethylamine (NDMA) & 9.430 & $62-75-9$ & 85.4 \\
Dimethylformamide (DMF) & 10.092 & $68-12-2$ & 76.6 \\
1-methyl-2-piperidinone & 11.047 & $931-20-4$ & 17.3 \\
1-methyl-1,2,4-triazole (MT) & 11.638 & $6086-21-1$ & 74.2 \\
Acetaldehyde- $N$-formyl- $N$-methydrazone (AFMH) & 12.171 & $16568-02-8$ & 55.1 \\
2-Nitroethanol & 12.956 & $625-48-9$ & 38.6 \\
$N$-methyl- $N$-nitro-ethanamine & 13.060 & $10595-95-6$ & 26.0 \\
1,3-dimethyl-Imidazolidinone & 13.087 & $80-73-9$ & 28.1 \\
\hline
\end{tabular}

The products are different in the excess of $\mathrm{O}_{3}$ and of $\mathrm{MMH}$. In the excess of $\mathrm{MMH}$, the major observed products are FDMH, FMH, DDZ, with minor NDMA and DMF. Meanwhile, in the excess of ozone, the major products are NDMA and DMF, with minor yields of $\mathrm{CH}_{3} \mathrm{NO}_{2}$. The NDMA and DMF 
are formed in $58 \%$ and $17.95 \%$ yields within $5 \mathrm{~min}$. From the observed products, the dominant reaction mechanism is $\mathrm{H}$-abstraction in the excess of $\mathrm{MMH}$, which can explain the high yields of hydrazones. Otherwise, in the excess of ozone, the main reaction mechanism includes not only $\mathrm{H}$-abstraction but also O-addition, which account for NDMA and DMF formation.

Furthermore, the observed products $\left(\mathrm{CH}_{3} \mathrm{COOH}, \mathrm{CH}_{3} \mathrm{OH}\right.$ and $\left.\mathrm{HCHO}\right)$ by FT-IR yields [22] in the presence of excess $\mathrm{O}_{3}$ accounted for $92 \%$ of the initial carbon in $\mathrm{MMH}$. However, these products are not detected by GC-MS in our experimental results, which probably because that these compounds are difficult to be separated from $\mathrm{O}_{2}$. At least $95 \%$ of the initial nitrogen in $\mathrm{MMH}$ could not be observed by FT-IR. Whereas, the dimethyl-compounds with nitrogen are detected by GC-MS which account for the initial nitrogen.

\subsubsection{The Variation of the Major Products Conversion Rates during Ozonation}

The reaction between MMH and ozone is too fast to be measured. In order to investigate the major products variation during ozonation, each run is flushed with ozone in each $15 \mathrm{~min}$. The results are shown in Figure 4.

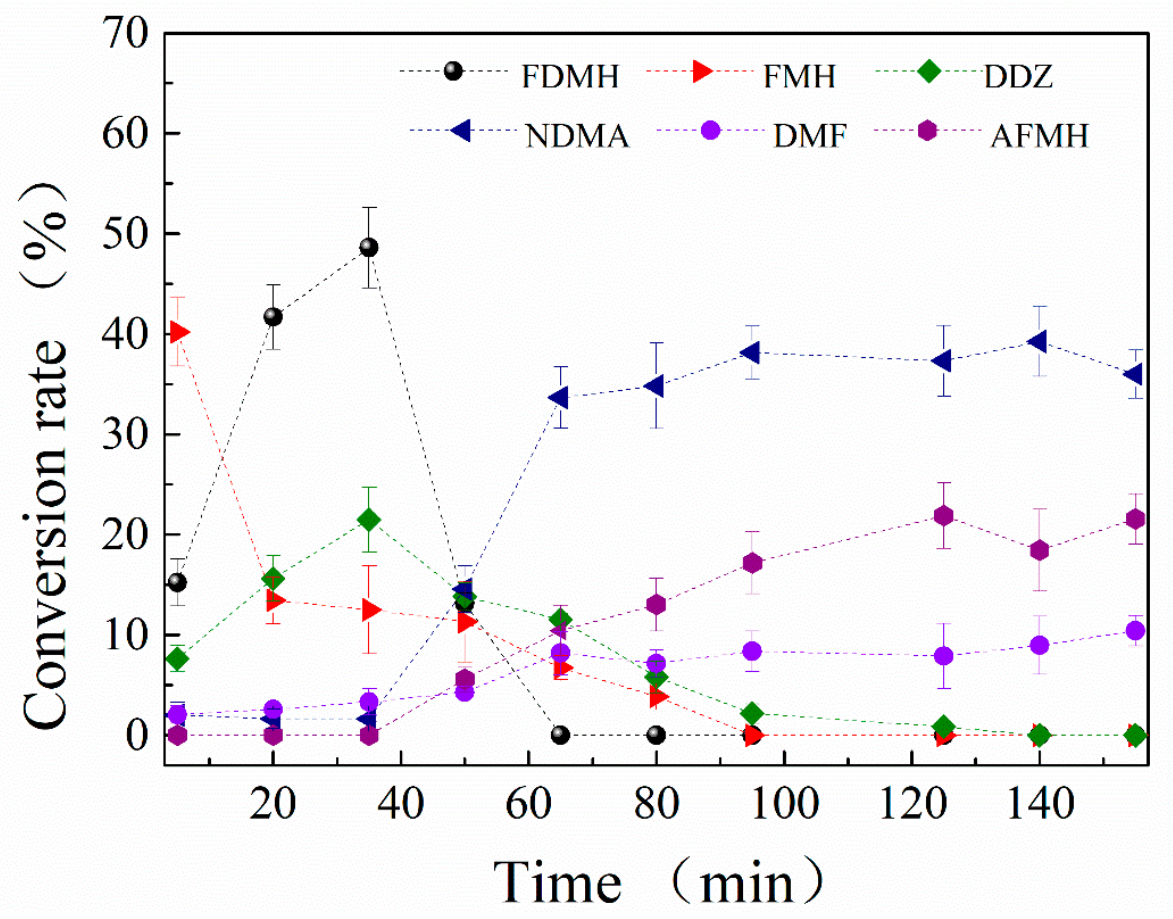

Figure 4. The curves of change in relative conversion rate of the products in $\mathrm{MMH}+\mathrm{O}_{3}$ system (flushed with ozone continuously).

Within $60 \mathrm{~min}$, the yields of FDMH, FMH and DDZ increase at the early stage and then decrease. Hence, the FDMH, FMH and DDZ are proposed to be the intermediates during the ozonation process. Moreover, the amounts of NDMA, DMF and AFMH increase during the ozonation process. When the FDMH decreases sharply within 40-60 min, the NDMA increases sharply. So the FDMH may convert to the NDMA during ozonation. This is consistent with the result that relatively high molar NDMA yields 95\% during FDMH ozonation in aqueous [23].

In conclusion, the FMH and DDZ may convert to DMF and AFMH. The ultimate products of MMH reaction with ozone are NDMA, DMF and AFMH. 


\subsubsection{Influence of Radical Trap (Propylene Alcohol) on NDMA Formation}

The influence of radical trap on the formation of NDMA, as a result of ozone reaction with MMH, is presented in Figure 5, which shows that the radical trap decreases NDMA formation and increases DMF formation significantly. The yields of NDMA occupy $58 \%$ in the absence of the radical trap and $30.7 \%$ in the presence of radical trap. This means that the radicals play a significant role in promoting the formation of NDMA in the $\mathrm{MMH}-\mathrm{O}_{3}$ system.

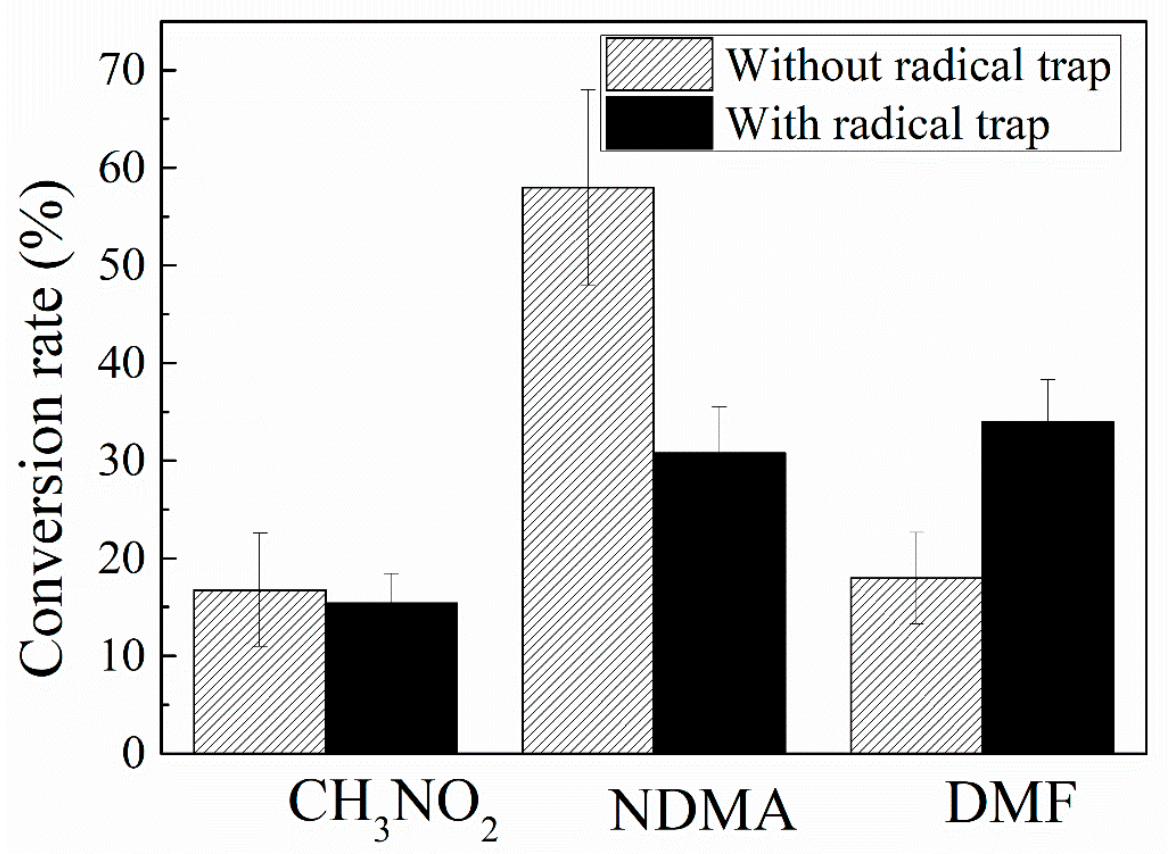

Figure 5. Influence of radical trap on NDMA formation $\left(\mathrm{O}_{3} / \mathrm{UDMH}\right.$ ratio $\left.\approx 10: 1\right)$.

\subsection{The Reactions between UDMH with Ozone}

\subsubsection{Products}

The runs are conducted in different $\mathrm{O}_{3} / \mathrm{UDMH}$ ratios (See Figure 6). The observed reaction rate of UDMH with $\mathrm{O}_{3}$ is as fast as that of $\mathrm{MMH}$ with $\mathrm{O}_{3}$. The relative yields of the organic products vary considerably at different $\mathrm{O}_{3} / \mathrm{UDMH}$ ratios. The details of the total products observed by GC-MS are listed in Table 3.
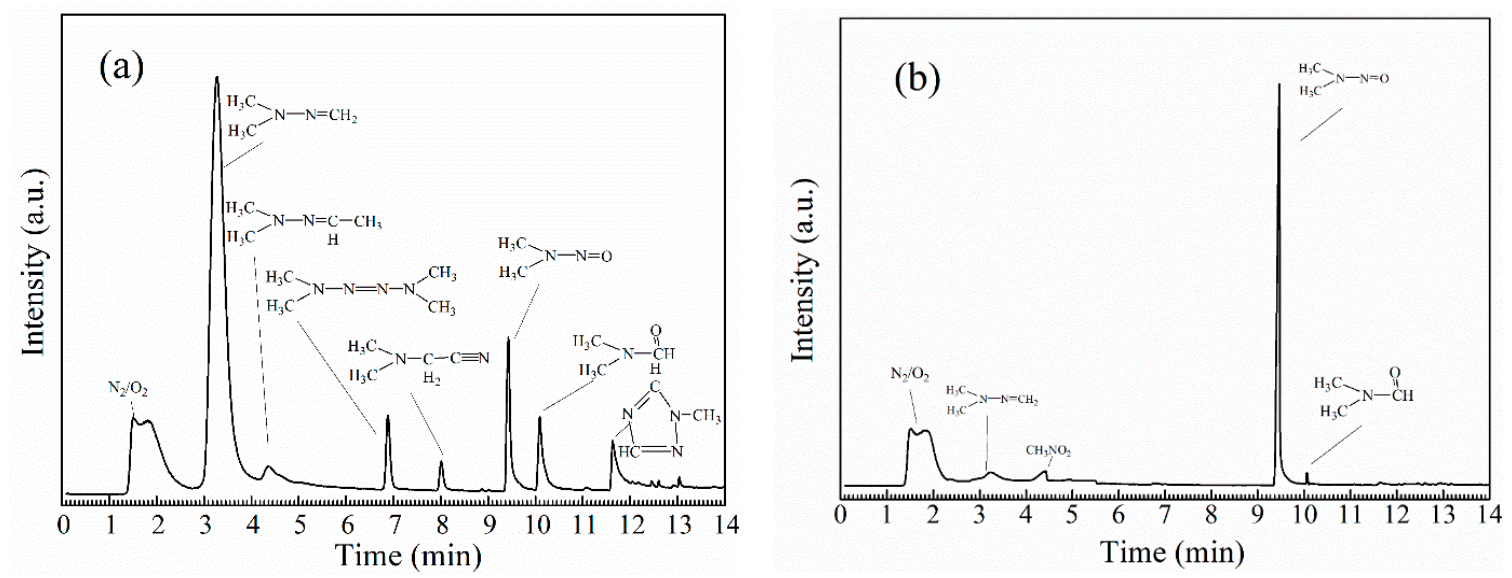

Figure 6. Gas chromatogram of the ozonation products of methylhydrazine: (a) $\mathrm{O}_{3} / \mathrm{UDMH} \approx 1: 1$; (b) $\mathrm{O}_{3} / \mathrm{UDMH} \approx 10: 1$. 
Table 3. Products of the reaction of 1,1-dimethyldrazine with ozone.

\begin{tabular}{lccc}
\hline Product & Peak/min & CAS No. & Pro. \\
\hline $\mathrm{N}_{2}$ & 2.241 & $7727-37-9$ & 98.0 \\
$\mathrm{H}_{2} \mathrm{O}$ & 2.740 & $7732-18-5$ & 97.2 \\
Dimethylamine (DMA) & 2.438 & $124-40-3$ & 70.5 \\
Formaldehyde dimethylhydrazone (FDMH) & 3.276 & $2035-89-4$ & 91.4 \\
Acetadehyde dimethylhydrazone (ADMH) & 4.363 & $7422-90-4$ & 85.5 \\
1,1,4,4-tetramethyl-1,2-tetrazene (TMT) & 6.888 & $6130-87-6$ & 44.0 \\
Dimethylamino-Acetonitrile & 8.013 & $924-64-7$ & 97.4 \\
$N$-nitrododimethylamine (NDMA) & 9.430 & $62-75-9$ & 90.8 \\
Dimethylformamide (DMF) & 10.092 & $68-12-2$ & 60.8 \\
1-methyl-1,2,4-triazole (MT) & 11.633 & $6086-21-1$ & 74.2 \\
$N$-formyl- $N$-methyl-Formamide & 12.890 & $18197-25-6$ & 40.9 \\
$N$-methyl-N-nitro-ethanamine & 13.060 & $10595-95-6$ & 26.0 \\
\hline
\end{tabular}

The major products observed in the $\mathrm{UDMH}-\mathrm{O}_{3}$ system are FDMH and NDMA, with minor yields TMT, DMF, MT. In the excess of UDMH, the major product is FDMH, while, in the excess of ozone, the major product is NDMA, whose molar conversion rate reaches $88.1 \%$. The large yields of FDMH is identified in the excess of UDMH by GC-MS, which may be the unidentified product with its strongest absorption [9] at $\sim 976 \mathrm{~cm}^{-1}$. The high yields of NDMA formation is consistent with that of EC Tuzon's study [7].

\subsubsection{The Variation of the Major Products Conversion Rates during Ozonation}

Similar to the $\mathrm{MMH}+\mathrm{O}_{3}$ system, the experiment is first conducted with low ozone concentration. After each sample, the chamber was injected with ozone. The results are shown in Figure 7.

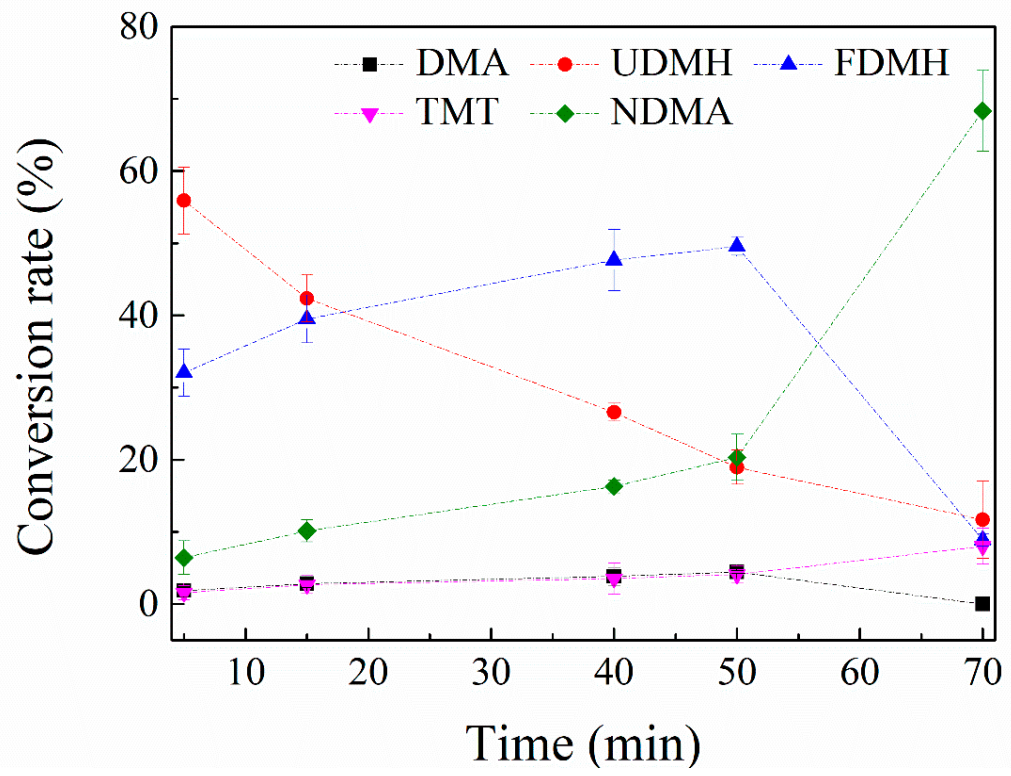

Figure 7. The curves of change in relative conversion rate of the products in $\mathrm{MMH}+\mathrm{O}_{3}$ system (flushed with ozone continuously).

With the consumption of UDMH, the main products FDMH, NDMA, DMA and TMT are generating. The concentration of FDMH (47.5\%) increases quickly at first $10 \mathrm{~min}$ and reaches to a peak at $40 \mathrm{~min}$ through a $20 \mathrm{~min}$ terrace, after which it decreases and is consumed over $50 \mathrm{~min}$. NDMA generates slowly at the first $40 \mathrm{~min}$ and then increases faster. The sharp increase of NDMA may be due to the FDMH consuming. The concentrations of TMT and DMA are almost unchanged 
with the ozone injection, indicating that they are in low reactivity with ozone. The molar NDMA conversion rate of $\mathrm{UDMH}$ is $57.4 \%$ after $70 \mathrm{~min}$.

\subsubsection{Influence of Radical Trap (Propylene Alcohol) on NDMA Formation}

The influence of radical trap on the formation of NDMA, as a result of ozone reaction with UDMH, is presented in Figure 8.

The influence of radical trap on NDMA formation from UDMH is opposite to that from $\mathrm{MMH}$. The radical traps increase NDMA formation. The yields of the other products are suppressed by the presence of the radical trap.

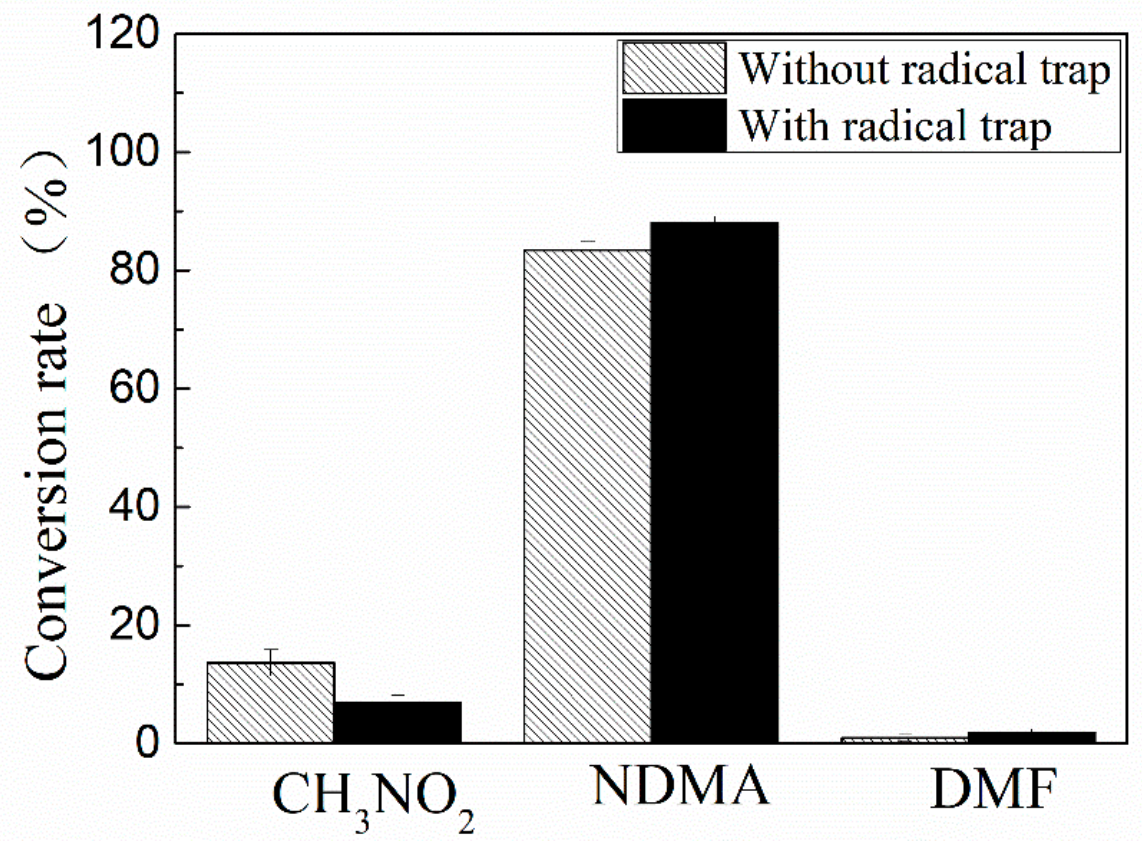

Figure 8. Influence of radical trap on the major products formation $\left(\mathrm{O}_{3} / \mathrm{UDMH}\right.$ ratio 5:1).

\subsection{Mechanism of the Reactions between Hydrazines with Ozone}

\subsubsection{Frontier Molecular Orbitals}

The frontier molecular orbitals [24] are often used to reveal the relationship between the electronic and geometric structures and to obtain qualitative information about the optical and electrical properties of molecules. The charges are computed by finding the electron population of each atom (Multiwfn) [25]. The result is that the energy gaps between the lowest unoccupied molecular orbital (LUMO) of $\mathrm{O}_{3}$ and the highest occupied molecular orbital (HOMO) of $\mathrm{H}_{2} \mathrm{H}_{4}, \mathrm{MMH}, \mathrm{UDMH}$ are smaller than that between the LUMO of $\mathrm{HH}, \mathrm{MMH}, \mathrm{UDMH}$ and the HOMO of $\mathrm{O}_{3}$, respectively. Thus, the reactions occur through the electron transfer from the $\mathrm{HOMO}$ of $\mathrm{H}_{2} \mathrm{H}_{4}, \mathrm{MMH}$ and UDMH to the LUMO of $\mathrm{O}_{3}$, suggesting an electrophilic attack of $\mathrm{O}_{3}$ to the hydrazines. The plots of energy levels, HOMO and LUMO are presented in Figure 9.

To evaluate the reactive site, we calculated the atom contribution by Hirshfeld method [26]. For $\mathrm{H}_{2} \mathrm{H}_{4}$, the contributions of $\mathrm{N} 1$ and $\mathrm{N} 2$ atom are similar, $40.65 \%$. For $\mathrm{MMH}$, the contributions of $\mathrm{N} 1, \mathrm{~N} 3, \mathrm{C} 6$ are $59.6 \%, 10.1 \%, 8.7 \%$, respectively. This indicates that the reactions based on attack of a electrophilic are favored on N1 atom. For UDMH, the contributions of N1, N2, C3, and C4 are 55.1\%, $8.6 \%, 7.7 \%, 7.4 \%$, respectively. Even though the N1 makes the highest contribution, it is difficult to attack due to spaces steric effect. The more the contribution to the HOMO, the easier it is to be oxidized. Therefore, the most reactive site may be the $\mathrm{N}-\mathrm{H}$ site. 
Overall, the possible initial step proceeds via $\mathrm{H}$-abstraction of methyl group or amino group. In addition, the $\mathrm{H}$-abstraction of $\mathrm{N}-\mathrm{H}$ bond is prior to that of $\mathrm{C}-\mathrm{H}$ bond.
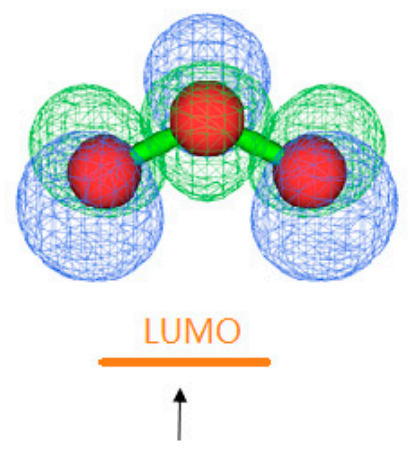

$3.72 \mathrm{eV}$

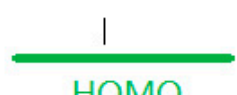

$\mathrm{HOMO}$

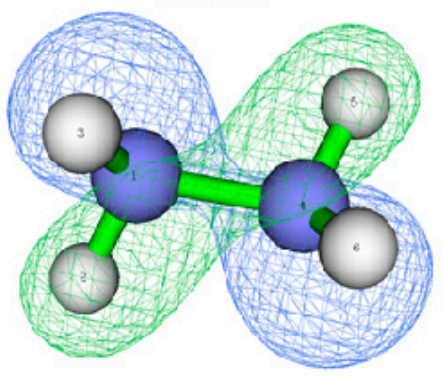

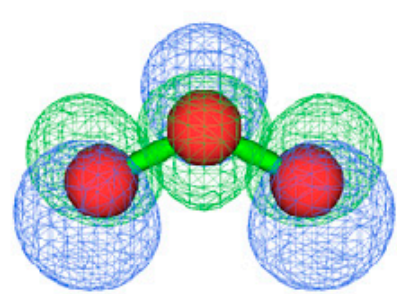

LUMO

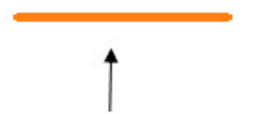

$4.43 \mathrm{eV}$

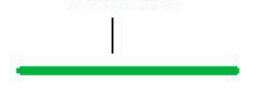

$\mathrm{HOMO}$

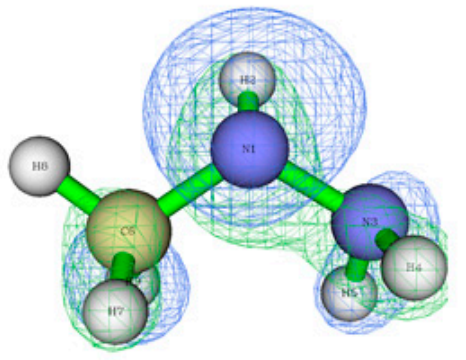

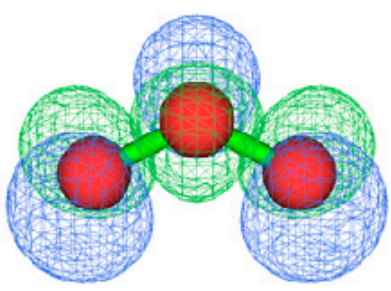

LUMO

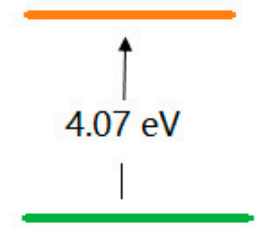

$\mathrm{HOMO}$

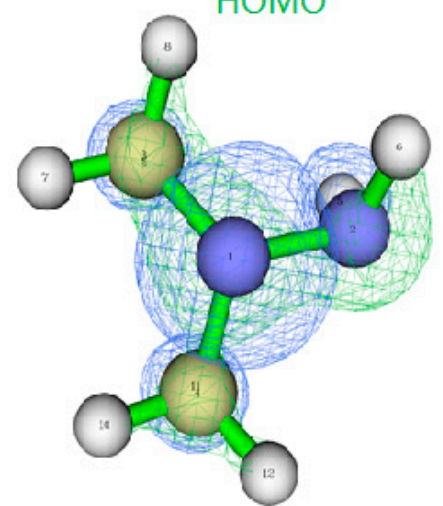

Figure 9. Frontier molecular orbital energies levels and the electronic distribution of hydrazines (HOMO) and ozone (LUMO) (energy unit is eV).

\subsubsection{The Products Formation Mechanism Initialed by H-Abstraction of N-H Bond}

Based on the frontier molecular orbitals results, the reactions between $\mathrm{H}_{2} \mathrm{H}_{4}, \mathrm{MMH}$ and UDMH with ozone are suggested to be initialed by $\mathrm{H}$-abstraction. The reaction of ozone with $\mathrm{N}-\mathrm{H}$ bond is preference to the reaction of ozone with $\mathrm{C}-\mathrm{H}$ bond. The oxidation of $\mathrm{N}-\mathrm{H}$ bond in $\mathrm{UDMH}-\mathrm{O}_{3}$ system leads to NDMA formation. The NDMA formation is mainly through $\mathrm{H}$-abstraction and O-addition. The detail NDMA formation mechanism is as follow:

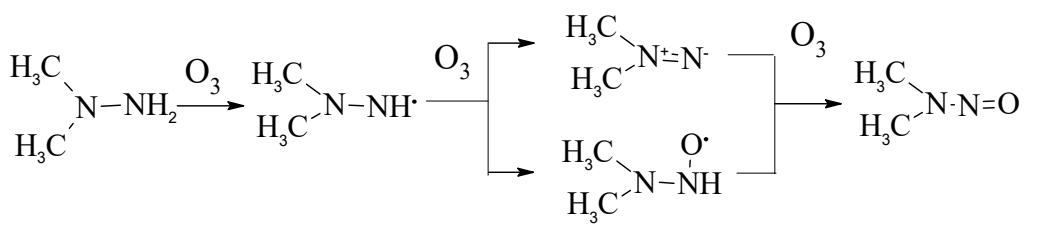

In the $\mathrm{MMH}-\mathrm{O}_{3}$ system, the formation way of methyl radicals is probably an important reaction pathway $[27,28]$. The atom contribution results indicate that the possible reaction site is at $\mathrm{N}_{1}-\mathrm{H}$ bond. The $\mathrm{H}$-abstraction of $\mathrm{N}_{1}-\mathrm{H}$ bond leads to the $\mathrm{H}_{3} \mathrm{C}-\mathrm{N}=\mathrm{N}$ formation, which cleave to $\mathrm{CH}_{3}$ and $\mathrm{N}_{2}$ (2). With the subsequent reactions (2), the methyl radicals formed which account for the high yields of the observed dimethylamine groups.

$$
\mathrm{H}_{3} \mathrm{C}-\mathrm{NHNH}_{2} \stackrel{\mathrm{O}_{3}}{\rightarrow} \mathrm{H}_{3} \mathrm{C}-\mathrm{N}^{-}-\mathrm{NH}_{2} \stackrel{\mathrm{O}_{3}}{\rightarrow} \mathrm{H}_{3} \mathrm{C}-\mathrm{N}=\mathrm{NH} \stackrel{\mathrm{O}_{3}}{\rightarrow} \mathrm{H}_{3} \mathrm{C}-\mathrm{N}=\mathrm{N}-\stackrel{\mathrm{O}_{3}}{\rightarrow} \mathrm{CH}_{3}+\mathrm{N} \equiv \mathrm{N}
$$


It is noticeable that $\mathrm{MMH}$ has also high potential for NDMA formation. The main reason is the methyl radical $\left(\mathrm{CH}_{3} \cdot\right)$ formation in $\mathrm{MMH}-\mathrm{O}_{3}$ system. The methyl process can promote more stable compounds with dimethylamine groups formation which finally generate NDMA, so that the products in $\mathrm{MMH}-\mathrm{O}_{3}$ system are similar to those in the $\mathrm{UDMH}-\mathrm{O}_{3}$ system.

\subsubsection{The Products Formation Mechanism Initialed by H-Abstraction of C-H Bond}

The observed non-negligible yields of $\mathrm{HCHO}$ indicate that the reactions initialed by $\mathrm{H}$-abstraction of $\mathrm{N}-\mathrm{H}$ bond cannot be the only process. The formation of these products can be attributed to the occurrence of an alternate reaction route initialed by $\mathrm{H}$-abstraction of $\mathrm{C}-\mathrm{H}$ bond.

Many researches [29-31] report that the atmospheric element of the $-\mathrm{CH}_{3}$ oxidation is $\mathrm{HCHO}$, which is detected by FT-IR in $\mathrm{MMH}-\mathrm{O}_{3}$ and $\mathrm{UDMH}-\mathrm{O}_{3}$ system. The $\mathrm{HCHO}$ formation pathway is:

$$
\mathrm{R}-\mathrm{CH}_{3} \stackrel{\mathrm{O}_{3}}{\rightarrow} \mathrm{R}-\mathrm{CH}_{2} \stackrel{\mathrm{O}_{3} / \mathrm{O}_{2}}{\rightarrow} \mathrm{R}-(\mathrm{O}) \mathrm{CH}_{2} \rightarrow \mathrm{R}+\mathrm{HCHO}
$$

As soon as $\mathrm{HCHO}$ formed [32,33], MMH and UDMH would immediately react with $\mathrm{HCHO}$, finally lead to the hydrazones formation. This can explain for the high yields of hydrazones observed by GC-MS.

$$
\mathrm{R}-\mathrm{NH}_{2}+\mathrm{HCHO} \rightarrow \mathrm{R}-\mathrm{N}=\mathrm{CH}_{2}+\mathrm{H}_{2} \mathrm{O}
$$

Furthermore, UDMH removes one methyl group to form $\mathrm{MMH}$. MMH after removing one methyl group converts to $\mathrm{N}_{2} \mathrm{H}_{4}$. In the $\mathrm{N}_{2} \mathrm{H}_{4}-\mathrm{O}_{3}$ system, the major products are $\mathrm{H}_{2} \mathrm{O}_{2}, \mathrm{~N}_{2}$ and $\mathrm{H}_{2} \mathrm{O}$ observed in experiments. The major ultimate fate of nitrogen in the hydrazines- $\mathrm{O}_{3}$ system is $\mathrm{N}_{2}$. Hence, the demethylation process is an important step for the conversion of UDMH and MMH to $\mathrm{N}_{2}$.

$$
\mathrm{H}_{3} \mathrm{C}^{-\mathrm{N}-\mathrm{NH}_{2}} \longrightarrow \stackrel{\mathrm{H}_{3} \mathrm{C}}{\mathrm{H}^{-}} \mathrm{C}^{-} \mathrm{N}-\mathrm{NH}_{2} \longrightarrow \mathrm{H}_{2} \mathrm{~N}-\mathrm{NH}_{2} \longrightarrow \mathrm{N}=\mathrm{N}
$$

Moreover, the formation pathway of another main products (DMF) would include N-N bond cleavage step. Based on the Sun's reports, the $\mathrm{C} \cdot \mathrm{H}_{2} \mathrm{NHNH}_{2}$ radical dissociates quickly to the products $\mathrm{H}_{2} \mathrm{C}=\mathrm{NH}+\mathrm{NH}_{2}$ with a low barrier of $12.0 \mathrm{kcal} / \mathrm{mol}[34,35]$.

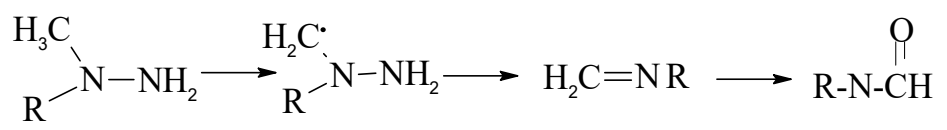

Thus, $\mathrm{H}_{2} \mathrm{C}=\mathrm{NH}$ is an important intermediate for DMF formation. DMF formation proceeds via $\mathrm{H}$-abstraction of $\mathrm{C}-\mathrm{H}$ bond.

\subsubsection{Influence of Radicals on NDMA Mechanism}

The heterolytic cleavage pathways explain the significant $\mathrm{HO}$. formation during ozonation of MMH and UDMH [36,37].

$$
\mathrm{R}-\mathrm{H}+\mathrm{O}_{3} \rightarrow \mathrm{HOOO} \rightarrow \mathrm{HO}^{\circ}+\mathrm{O}_{2}
$$

In the presence of excess ozone, the radical trap would increase the NDMA yields from UDMH, and decrease the NDMA yields from MMH. This may indicate that HO. plays a key role in destruction of the $\mathrm{C}-\mathrm{H}$ and $\mathrm{N}-\mathrm{H}$ bonds.

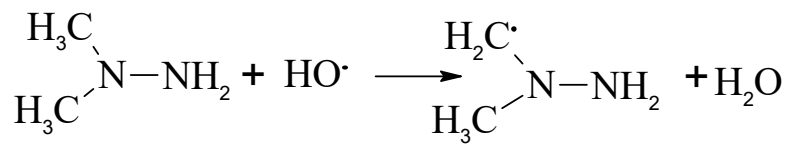




$$
\stackrel{\mathrm{H}^{\prime}}{\mathrm{C}} \mathrm{N}-\mathrm{NH}_{2}+\mathrm{HO} \longrightarrow \mathrm{H}_{3} \mathrm{C}-\mathrm{N}^{-}-\mathrm{NH}_{2}+\mathrm{H}_{2} \mathrm{O}
$$

The difference between UDMH and MMH is the $\left(\mathrm{CH}_{3}\right)_{2} \mathrm{~N}$ group and $\left(\mathrm{CH}_{3}\right) \mathrm{HN}$ group. As shown in (5), UDMH could convert to NDMA directly by the oxidation the amino groups, with high yields $(88 \%)$. The reaction between $\mathrm{HO}$ - and the $\mathrm{C}-\mathrm{H}$ bonds of $\mathrm{UDMH}$ leads to $\mathrm{HCHO}$ and other products (amines and $\mathrm{CH}_{3} \mathrm{NO}_{2}$ et al.) formation. Meanwhile, for $\mathrm{MMH}$, the reaction between $\mathrm{HO}$. and $\mathrm{N}-\mathrm{H}$ bond of MMH can promote the methyl radical formation, finally leads to the increase of NDMA yields.

\section{Conclusions}

The products of $\mathrm{N}_{2} \mathrm{H}_{4}, \mathrm{MMH}$ and UDMH reaction with ozone are detected by GC-MS. The major products in the presence of excess hydrazines or excess ozone, the radical influence on NDMA formation are investigated. The reaction mechanisms which account for the major products (especially NDMA) are discussed. More specific conclusions are follows:

Apart from the products (NDMA, $\mathrm{N}_{2} \mathrm{O}$ et al.) detected by FT-IR, the new compounds (hydrazones, formamides, dimethylamine, 1,1,4,4-tetramethyl-1,2-tetrazene, dimethylamino-acetonitrile, $\mathrm{N}_{2}$, $\mathrm{H}_{2} \mathrm{O}$, et al.) are identified by GC-MS. And the relative yields of the organic products vary considerably depending on the $\mathrm{O}_{3} / \mathrm{MMH}$ or UDMH ratios.

The ozonation of UDMH yields high amounts of NDMA $(>50 \%)$. It is noticeable that MMH also has potential for NDMA formation in the presence of excess ozone.

Radicals play an important role in NDMA formation. It can hinder NDMA formation from UDMH and promote NDMA formation from MMH. It may be due to that HO- makes many contributions to destructing $\mathrm{C}-\mathrm{H}$ and $\mathrm{N}-\mathrm{H}$ bonds.

An analysis of the energy gap between the frontier molecular orbitals of the reactants indicates that the oxidations of the hydrazines as well as N-H and C-H bonds are initiated by hydrogen atom abstraction. The oxidation of $\mathrm{N}-\mathrm{H}$ bond is the most favorable.

The major ultimate fate of nitrogen $\left(\mathrm{N}_{2} \mathrm{H}_{4}, \mathrm{MMH}, \mathrm{UDMH}\right)$ may be $\mathrm{N}_{2}$ through the demethylation process. However, the reaction of ozone with $\mathrm{N}-\mathrm{H}$ bonds is preference to that with $\mathrm{C}-\mathrm{H}$ bonds. NDMA and methyl radical formation proceeds via $\mathrm{H}$-abstraction from $\mathrm{N}-\mathrm{H}$ bonds. The $\mathrm{N}_{2}$, formaldehyde, amines, formamide and hydrazones formation proceeds via $\mathrm{H}$-abstraction from $\mathrm{C}-\mathrm{H}$ bonds.

Author Contributions: Formal Analysis, D.H.; Investigation, D.H.; Data Curation, Y.Y.; Writing-Original Draft Preparation, D.H.; Supervision, X.G., X.L. and X.W.; Funding Acquisition, Z.X.

Acknowledgments: Authors thank for Mis Yang for the English checking.

Funding: This research was financially supported by China Postdoctoral Science Foundation (grant No. 2016M600084).

Conflicts of Interest: The authors declare no competing financial interests.

\section{References}

1. Catoire, L.; Chaumeix, N.; Paillard, C. Journal of Propulsion and Power-20(1):87-PDF (AIAA). J. Propuls. Power 2004, 20, 87-92. [CrossRef]

2. Collins, G.E.; Rosepehrsson, S.L. Fluorescent detection of hydrazine, monomethylhydrazine, and 1,1dimethylhydrazine by derivatization with aromatic dicarbaldehydes. Analyst 1994, 119, 1907-1913. [CrossRef]

3. Holtzclaw, J.R.; Rose, S.L.; Wyatt, J.R.; Rounbehler, D.P.; Fine, D.H. Simultaneous determination of hydrazine, methylhydrazine, and 1,1-dimethylhydrazine in air by derivatization/gas chromatography. Anal. Chem. 1984, 56, 2952-2956. [CrossRef] [PubMed]

4. Carlsen, L.; Kenessov, B.N.; Batyrbekova, S.Y. A QSAR/QSTR study on the human health impact of the rocket fuel 1,1-dimethyl hydrazine and its transformation products Multicriteria hazard ranking based on partial order methodologies. Environ. Toxicol. Pharmacol. 2009, 27, 415-423. [CrossRef] [PubMed] 
5. Lars, C.; Kenessov, B.N.; Ye, B.S. A QSAR/QSTR Study on the Environmental Health Impact by the Rocket Fuel 1,1-Dimethyl Hydrazine and its Transformation Products. Environ. Health Insights 2008, 1, 11.

6. Hong, Y.; Kim, K.H.; Sang, B.I.; Kim, H. Simple quantification method for N-nitrosamines in atmospheric particulates based on facile pretreatment and GC-MS/MS. Environ. Pollut. 2017, 226, 324-334. [CrossRef] [PubMed]

7. Pitts, J.N., Jr.; Tuazon, E.C.; Carter, W.P.L.; Winer, A.M.; Harris, G.W. Atmospheric Chemistry of Hydrazines: Gas Phase Kinetics and Mechanistic Studies; California Univ Riverside Statewide Air Pollution Research Center: Riverside, CA, USA, 1980.

8. Coleman, D.J.; Judeikis, H.S.; Lang, V. Gas-Phase Rate Constant Measurements for Reactions of Ozone with Hydrazines; Aerospace Corp el Segundo ca el Segundo Technical Operations: El Segundo, CA, USA, 1996.

9. Tuazon, E.C.; Carter, W.P.L.; Winer, A.M.; Pitts, J.N. Reactions of hydrazines with ozone under simulated atmospheric conditions. Environ. Sci. Technol. 1981, 15, 823-828. [CrossRef]

10. Marti, E.J.; Pisarenko, A.N.; Peller, J.R.; Dickenson, E.R. N-nitrosodimethylamine (NDMA) formation from the ozonation of model compounds. Water Res. 2015, 72, 262-270. [CrossRef] [PubMed]

11. Lim, S.; Lee, W.; Na, S.; Shin, J.; Lee, Y. N-nitrosodimethylamine (NDMA) formation during ozonation of $\mathrm{N}, \mathrm{N}$-dimethylhydrazine compounds: Reaction kinetics, mechanisms, and implications for NDMA formation control. Water Res. 2016, 105, 119-128. [CrossRef] [PubMed]

12. Yoon, S.; Tanaka, H. Formation of $N$-nitrosamines by chloramination or ozonation of amines listed in Pollutant Release and Transfer Registers (PRTRs). Chemosphere 2014, 95, 88-95. [CrossRef] [PubMed]

13. Liu, Y.D.; Zhong, R. Comparison of $N$-nitrosodimethylamine formation mechanisms from dimethylamine during chloramination and ozonation: A computational study. J. Hazard. Mater. 2017, 321, 362-370. [CrossRef] [PubMed]

14. Zhang, S.; Yu, G.; Chen, J.; Wang, B.; Huang, J.; Deng, S. Unveiling formation mechanism of carcinogenic $\mathrm{N}$-nitrosodimethylamine in ozonation of dimethylamine: A density functional theoretical investigation. J. Hazard. Mater. 2014, 279, 330-335. [CrossRef] [PubMed]

15. Yu, H.; Ge, P.; Chen, J.; Xie, H.; Luo, Y. The degradation mechanism of sulfamethoxazole under ozonation: A DFT study. Environ. Sci. Process Impacts 2017, 19, 379-387. [CrossRef] [PubMed]

16. Rodin, I.A.; Smirnov, R.S.; Smolenkov, A.D.; Shpigun, O.A. Transformation of unsymmetrical dimethylhydrazine in soils. Eurasian Soil Sci. 2012, 45, 386-391. [CrossRef]

17. Smolenkov, A.D.; Smirnov, R.S.; Rodin, I.A.; Tataurova, O.G.; Shpigun, O.A. Effect of sample preparation conditions on the determination of the total concentrations of unsymmetrical dimethylhydrazine in soils. J. Anal. Chem. 2012, 67, 6-13. [CrossRef]

18. Kenessov, B.; Alimzhanova, M.; Sailaukhanuly, Y.; Baimatova, N.; Abilev, M.; Batyrbekova, S.; Carlsen, L.; Tulegenov, A.; Nauryzbayev, M. Transformation products of 1,1-dimethylhydrazine and their distribution in soils of fall places of rocket carriers in Central Kazakhstan. Sci. Total Environ. 2012, 427-428, 78-85. [CrossRef] [PubMed]

19. Rodin, I.A.; Anan'Eva, I.A.; Smolenkov, A.D.; Shpigun, O.A. Determination of the products of the oxidative transformation of unsymmetrical dimethylhydrazine in soils by liquid chromatography/mass spectrometry. J. Anal. Chem. 2010, 65, 1405-1410. [CrossRef]

20. Ul'yanovskii, N.V.; Kosyakov, D.S.; Pokryshkin, S.A.; Bogolitsyn, K.G. Determination of transformation products of 1,1-dimethylhydrazine by gas chromatography-tandem mass spectrometry. J. Anal. Chem. 2015, 70, 1553-1560. [CrossRef]

21. Kosyakov, D.S.; Ul’Yanovskii, N.V.; Pokryshkin, S.A.; Lakhmanov, D.E.; Shpigun, O.A. Rapid determination of 1,1-dimethylhydrazine transformation products in soil by accelerated solvent extraction coupled with gas chromatography-tandem mass spectrometry. Int. J. Environ. Anal. Chem. 2015, 95, 1321-1337. [CrossRef]

22. Tuazon, E.C.; Carter, W.P.L.; Brown, R.V.; Atkinson, R.; Winer, A.M. Atmospheric Reaction Mechanisms of Amine Fuels; Atmospheric Reaction Mechanisms of Amine Fuels; California Univ Riverside Air Pollution Research Center: Riverside, CA, USA, 1982.

23. Kosaka, K.; Fukui, K.; Kayanuma, Y.; Asami, M.; Akiba, M. N-Nitrosodimethylamine Formation from Hydrazine Compounds on Ozonation. Ozone Sci. Eng. 2014, 36, 215-220. [CrossRef]

24. Wang, W.Y.; Kan, Y.H.; Wang, L.; Sun, S.L.; Qiu, Y.Q. Large Nonlinear Optical Responses of Dimers Bearing a Donor and Acceptor: Long, Intradimer Multicenter Bonding. J. Phys. Chem. C 2014, 118, 28746-28756. [CrossRef] 
25. Lu, T.; Chen, F. Multiwfn: A multifunctional wavefunction analyzer. J. Comput. Chem. 2012, 33, 580-592. [CrossRef] [PubMed]

26. Bultinck, P. The Hirshfeld-I method: Atoms in molecules and chemical bonding perspective. Acta Crystallogr. 2011, 67, C85-C86. [CrossRef]

27. Lambert, C.E.; Shank, R.C. Role of formaldehyde hydrazone and catalase in hydrazine-induced methylation of DNA guanine. Carcinogenesis 1988, 9, 65. [CrossRef] [PubMed]

28. Gomes, L.F.; Augusto, O. Formation of methyl radicals during the catalase-mediated oxidation of formaldehyde hydrazone. Carcinogenesis 1991, 12, 1351-1353. [CrossRef] [PubMed]

29. Martínezavilés, M.; And, R.R.; Francisco, J.S. Atmospheric Oxidation Mechanism of Bromoethane. J. Phys. Chem. A 2007, 111, 11652. [CrossRef] [PubMed]

30. Kagiya, T.; Yokoyama, N.; Takemoto, K. Radiation-Induced Degradation of Poly (Ethylene Oxide) in the Atmosphere of Chlorine Compounds (Special Issue on Physical, Chemical and Biological Effects of Gamma Radiation, XVI). Bull. Inst. Chem. Res. 1976, 54, 15-22.

31. Carlier, P.; Hannachi, H.; Mouvier, G. The chemistry of carbonyl compounds in the atmosphere-A review. Atmos. Environ. 1986, 20, 2079-2099. [CrossRef]

32. Sisler, H.H.; Mathur, M.A.; Jain, S.R.; Greengard, R. Studies of the chloramination of dimethylamine and 1,1-dimethylhydrazine. Ind. Eng. Chem. Prod. Res. Dev. 1981, 20, 181-185. [CrossRef]

33. Fan, J.; Zhang, R. Density functional theory study on $\mathrm{OH}$-initiated atmospheric oxidation of m-xylene. J. Phys. Chem. A 2008, 112, 4314-4323. [CrossRef] [PubMed]

34. Sun, H.; Law, C.K. Thermochemical and kinetic analysis of the thermal decomposition of monomethylhydrazine: An elementary reaction mechanism. J. Phys. Chem. A 2007, 111, 3748. [CrossRef] [PubMed]

35. Sun, H.; Catoire, L.; Law, C.K. Thermal decomposition of monomethylhydrazine: Shock tube experiments and kinetic modeling. Int. J. Chem. Kinetics 2009, 41, 176-186. [CrossRef]

36. Nelander, B.; Engdahl, A.; Svensson, T. The HOOO radical. A matrix isolation study. Chem. Phys. Lett. 2000, 332, 403-408. [CrossRef]

37. Varner, M.E.; Harding, M.E.; Vázquez, J.; Gauss, J.; Stanton, J.F. Dissociation energy of the HOOO radical. J. Phys. Chem. A 2009, 113, 11238-11241. [CrossRef] [PubMed]

(C) 2018 by the authors. Licensee MDPI, Basel, Switzerland. This article is an open access article distributed under the terms and conditions of the Creative Commons Attribution (CC BY) license (http://creativecommons.org/licenses/by/4.0/). 